\title{
Synthesis, Structure and Photocatalytic Property of a New Hybrid Compound Based on Unusual Bi-Silver-Capped \\ Polyoxometalates
}

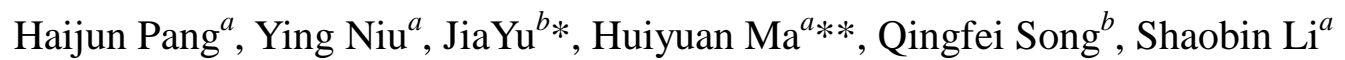

${ }^{a}$ College of Chemical and Environmental Engineering, Harbin University of Science and Technology, Harbin, 150040, China

${ }^{b}$ College of Aerospace and Civil Engineering, Harbin Engineering University, Harbin, 150001, China

*Correspondence to: J. Yu, Tel./fax.: 86-451-55535158;

**Correspondence to: H.Y. Ma, Tel./fax: 86-0451-86392716;

E-mail addresses: yujiaworld@163.com, mahy017@163.com.

\section{Abstract}

A new compound based on capped polyoxometalates (POMs), $\left[\mathrm{Ag}(\text { phen })_{2}\right]_{2}$ (Agphen $)_{2} \mathrm{SiW}_{12} \mathrm{O}_{40}$ (phen $=1,10$-phenanthroline), has been hydrothermally synthesized and characterized by single-crystal X-ray diffraction analysis, infrared spectrum, UV-vis electronic spectrum, elemental analyses, and powder X-ray diffraction pattern. The structural feature of compound $\mathbf{1}$ is that each $\left[\mathrm{SiW}_{12} \mathrm{O}_{40}\right]^{4-}\left(\mathrm{SiW}_{12}\right)$ cluster capped by two (Agphen) ${ }^{+}$fragments. To the best of our knowledge, the compound 1 represents the first example of hybrid compound based on bi-silver-capped POMs to date. The photocatalytic properties of compound 1 were also investigated in detail and the results of photocatalytic experiment show that compound $\mathbf{1}$ can be used as a photocatalyst towards the decomposition of organic pollutant methylene blue (MB).

Keywords: Bi-silver-capped polyoxometalate; Photocatalytic property; Keggin

Polyoxometalates (POMs), a large family of metal-oxygen clusters with diversity structures, exhibit versatile applications [1-3], especially in catalysis and electrochemistry. Recently, in the filed of POMs, more and more attention has been focused on the design and synthesis of new POM-based inorganic-organic hybrid 
compounds with desirable structures and properties. In this field, the hybrid compounds based on capped POMs become extraordinarily promising because of their changeable and controllable structures as well as their predominant properties introduced by capping moieties [4]. These facts have provided a powerful impetus for the creation of novel hybrid compounds based on capped POMs, and thus many significant results have been achieved by the efforts of inorganic chemists [5-27]. An excellent example is that a series of hybrid compounds constructed from bicapped POMs to tetracapped ones were reported by Wang et al. in 2003 [11]. Subsequently, thanks to the work of Peng et al., a novel asymmetrically modified bivanadium-capped Keggin polyoxometalate has been reported [13]. However, the capping metals in these compounds were generally restricted to Mo or V atoms, except for the several examples (see the summarization of these compounds based on capped POMs in Table $\mathrm{S} 1$ ), in which the capping metals are $\mathrm{Ni}, \mathrm{Sb}, \mathrm{Nb}, \mathrm{As}$ and $\mathrm{Ag}$ atoms. As is well known, $\mathrm{Ag}^{+}$ion is widely applied in luminescent, catalytic and antibacterial materials [28,29]. Further, $\mathrm{Ag}^{+}$ion possesses flexible coordination geometries and high affinity to $\mathrm{O}$ and $\mathrm{N}$ donors, which may easily form covalent links between $\mathrm{Ag}^{+}$ions and POMs/ligands [30]. Hence, these properties endow that $\mathrm{Ag}^{+}$ ions are good synthons as capping metals for construction of novel hybrid compounds based on silver-capped POMs. Nevertheless, to the best of our knowledge, up to now, only one such hybrid compound has been reported Cao et al. in 2008 [31], namely, $\left\{\mathrm{Ag}(\text { phen })_{2}\right\}_{2}\left\{[\mathrm{Ag}(\text { phen })]_{2}\left[\mathrm{PMo}_{12} \mathrm{O}_{40}\right]\right\}(2)$, which shows a chain structure based on mono-silver-capped phosphomolybdates and displays fascinating orange luminescent property at ambient temperature (Scheme S1).

Herein, we communicate the preparation and structure of a new hybrid compound based on silver-capped POMs, $\left[\mathrm{Ag}(\mathrm{phen})_{2}\right]_{2}(\text { Agphen })_{2} \mathrm{SiW}_{12} \mathrm{O}_{40}$ (phen = 1,10-phenanthroline) (1), which is after the compound 2 reported by Cao et al. [31], but compound $\mathbf{1}$ is based on bi-silver-capped silicotungstate (see Scheme S1). Furthermore, the photocatalytic property of compound $\mathbf{1}$ towards photodecomposition of organic pollutant MB was investigated in detail.

Compound 1 was hydrothermally synthesized with a mixture of 
$\mathrm{H}_{4}\left[\mathrm{SiW}_{12} \mathrm{O}_{40}\right] \cdot 12 \mathrm{H}_{2} \mathrm{O}, \mathrm{AgNO}_{3}$, and phen in water at $160{ }^{\circ} \mathrm{C}$ for 3 days (supplementary material). And compound $\mathbf{1}$ crystallizes in the triclinic space group $P \overline{1}$ (supplementary material). Single-crystal X-ray diffraction analysis reveals that compound 1 consists of a silicotungstate polyanion $\mathrm{SiW}_{12}$, four $\mathrm{Ag}^{+}$cations and six phen ligands, as shown in Fig. 1. The $\mathrm{SiW}_{12}$ polyanion exhibits the well-known $\alpha$-Keggin type structure, consisting of central $\mathrm{SiO}_{4}$ tetrahedron corner-sharing four triad $\left\{\mathrm{W}_{3} \mathrm{O}_{13}\right\}$ clusters. The central atom $\mathrm{Si}$ is disorderly surrounded by a cube of eight oxygen atoms, with each oxygen site half-occupied. There are two crystallographically independent Ag atoms in structure of compound 1, which exhibit an identical six-coordination in distorted octahedral geometries, but their coordination environments are entirely different. Namely, the $\operatorname{Ag}(1)$ is coordinated by two nitrogen atoms from a phen molecule and four oxygen atoms from a $\mathrm{SiW}_{12}$ polyanion. While the $\operatorname{Ag}(2)$ is coordinated by four nitrogen atoms from two phen molecules and two oxygen atoms from a $\mathrm{SiW}_{12}$ polyanion. The bond lengths and angles around the $\mathrm{Ag}$ ions are in the ranges of 1.96(2)-2.36(2) $\AA(\mathrm{Ag}-\mathrm{N}), 2.31(2)-2.58(2) \AA(\mathrm{Ag}-\mathrm{O})$, $72.1(8)-178.8(8)^{\circ}(\mathrm{N}-\mathrm{Ag}-\mathrm{N})$ and $84.5(7)-173.5(8)^{\circ}(\mathrm{N}-\mathrm{Ag}-\mathrm{O})$.

[Insert Fig. 1]

An interesting structural feature of compound $\mathbf{1}$ is its bi-silver-capped silicotungstate polyanion, which can be described in detail as follows: as mentioned above, the $\operatorname{Ag}(1)$ atom is coordinated by two nitrogen atoms from one phen molecule to form a $[\operatorname{Ag}(1) \text { phen }]^{+}$coordination fragment, while the $\operatorname{Ag}(2)$ atom is coordinated by four nitrogen atoms from two phen molecules to give birth to a $\left[\operatorname{Ag}(2)(\text { phen })_{2}\right]^{+}$ coordination fragment. Each $[\mathrm{Ag}(1) \text { phen }]^{+}$coordination fragment is further coordinated by four bridging oxygen atoms from a $\mathrm{SiW}_{12}$ polyanion to construct square pyramidal motives, and there are two such square pyramidal motives capping on the two opposites points of each $\mathrm{SiW}_{12}$ polyanion. Consequently, a novel bi-silver-capped silicotungstate polyanion [(Agphen) $\left.{ }_{2} \mathrm{SiW}_{12} \mathrm{O}_{40}\right]^{2-}$ is obtained (Fig. 2). Herein, in the structure of polyanion $\left[\left(\text { Agphen }{ }_{2} \mathrm{SiW}_{12} \mathrm{O}_{40}\right]^{2-}\right.$, capping silver atoms may play a great role in inducing the polyanion to polarize and making the surface of polyanion modified by other transition metal complexes with ease. And thus, the 
$\left[(\text { Agphen })_{2} \mathrm{SiW}_{12} \mathrm{O}_{40}\right]^{2-}$ polyanion is further modified by two $\left[(\text { Agphen })_{2}\right]_{2}{ }^{2+}$ (Fig. 1). Furthermore, there exist $\pi \cdots \pi$ interactions between the almost parallel phen rings from adjacent $[\operatorname{Ag}(1) \text { phen }]^{+}$coordination fragments. And the centroid-centroid distance is $3.65 \AA$ (see Fig. S1), which is usual ranges of $\pi \cdots \pi$ interactions [32]. As a result, a 1D supramolecular chain is formed (Fig. 3).

[Insert Fig. 2]

[Insert Fig. 3]

It is well known that POMs often show photocatalytic activity in decomposition of waste organic molecules so as to purify the water resources. Accordingly, we selected an organic dye methylene blue (MB) as a model pollutant to evaluate its photodecomposition under UV irradiation. Before we did the photocatalytic experiments, the characterizations of infrared spectrum, UV-vis electronic spectrum, elemental analyses, and powder X-ray diffraction pattern had been performed (please see details in supplementary material). As shown in Fig. 4, the absorption peaks of MB aqueous solution decreased gradually and the decolorization of MB aqueous solution became obvious with increasing time under UV irradiation with compound $\mathbf{1}$. The decomposition rate of $\mathrm{MB}(\mathrm{K})$ can be expressed as $\mathrm{K}=\left(\mathrm{C}_{0}-\mathrm{C}\right) / \mathrm{C}_{0}$, where $\mathrm{C}_{0}$ represents the $\mathrm{UV}$-vis absorption intensity of $\mathrm{MB}$ at the initial time and $\mathrm{C}$ is the intensity at a given time. It can be seen that the photocatalytic decomposition rate is $70.25 \%$ for compound 1. In contrast, the rates of photocatalytic decomposition without compound $\mathbf{1}$ is $13.15 \%$, after UV irradiation for the same time, which reveals that the formation of organic-inorganic hybrid compound based on POMs could improve the photocatalytic decomposition rate of MB. The degradation of the MB dye occurs by the hydroxyl radicals and the superoxides (see the photocatalytic mechanisms in supplementary material).

\section{[Insert Fig. 4]}

In summary, a new hybrid compound based on silver-capped POMs has been obtained from hydrothermally synthesis method. The compound 1 represents the first example of hybrid compound based on bi-silver-capped POMs to date. Also, there exist $\pi \cdots \pi$ interactions in its structure, which have an important influence on linking 
the low-dimensional entities into a supramolecular chain. In addition, compound $\mathbf{1}$ shows good photocatalytic activity toward the decomposition of organic pollutant methylene blue. With hindsight, we can imagine that more new hybrid compounds based on capped POMs could be prepared by replacement of capping metallic-organic segments and/or by appropriate choices of different POMs in the near future. Further work in this field is underway in our laboratory.

\section{Acknowledgments.}

This work was financially supported by the NSF of China (21371041 and 51102059), the science and technology innovation foundation of Harbin (2014RFXXJ076), youth scholar backbone supporting plan project for general universities of Heilongjiang Province (1254G020) and the SF for the Young Innovative Talents of HUST (No.201307).

\section{Appendix A. Supplementary material}

Supplementary data associated with this article can be found in the online version.

\section{References}

[1] R.M. Yu, X.F. Kuang, X.Y. Wu, C.Z. Lu, J.P. Donahue, Stabilization and Immobilization of Polyoxometalates in Porous Coordination Polymers Through Host-guest Interactions, Coord. Chem. Rev. 253 (2009) 2872-2890.

[2] A. Dolbecq, E. Dumas, C.R. Mayer, P. Mialane, Hybrid organic-inorganic polyoxometalate compounds: from structural diversity to applications, Chem. Rev. 110 (2010) 6009-6048.

[3] H.N. Miras, J. Yan, D.L. Long, L. Cronin, Engineering polyoxometalates with emergent properties, Chem. Soc. Rev. 41 (2012) 7403-7430.

[4] J. Lehmann, A. Gaita-Ariño, E. Coronado, D. Loss. Quantum computing with molecular spin systems, J. Mater. Chem. 19 (2009) 1672-1677.

[5] C.M. Liu, D.Q. Zhang, D.B. Zhu. One- and two-dimensional coordination polymers constructed from bicapped Keggin mixed molybdenum-vanadium heteropolyoxoanions and polynuclear copper(I) clusters bridged by asymmetrical bipyridine (2,4'-bipy and 2,3'-bipy) Ligands, Cryst. Growth Des. 6 (2006) 524-529. 
[6] A. K. Iyer, S.C. Peter. Two-dimensional bicapped supramo- lecular hybrid semiconductor material constructed from the insulators $\alpha$-Keggin polyoxomolybdate and 4,4'-Bipyridine, Inorg. Chem. 53 (2014) 653-660.

[7] Z.G. Han, X.Q. Chang, J.S. Yan, K.N. Gong, C. Zhao, X.L. Zhai. An unusual metallic oxygen cluster consisting of a $\left\{\mathrm{AlMo}_{12} \mathrm{O}_{40}\left(\mathrm{MoO}_{2}\right)\right\}$. Inorg. Chem. 53 (2014) 670-672.

[8] Y.B. Liu, Y. Wang, L.N. Xiao, Y.Y. Hu, L.M. Wang, D.C. Zhao, H.Y. Guo, X.B. Cui, C.L. Pan, J.Q. Xu. A novel chain structure constructed from copper complexes and dimers based on bi-capped Keggin clusters. Inorg. Chem. Comm. 35 (2013) 204-207.

[9] Y. Ding, J.X. Meng,W.L. Chen, E.B. Wang. Controllable assembly of four new POM-based supramolecular compounds by altering the POM secondary building units from pseudo-Keggin to classical Keggin, CrystEngComm, 13 (2011) $2687-2692$.

[10] X.J. Gu, J. Peng, Z.Y. Shi, Y.H. Chen, Z.G. Han, E.B. Wang, J.F. Ma, N.H. Hu. Target syntheses of saturated Keggin polyoxometalate-based extended solids. Inorg. Chim. Acta. 358 (2005) 3701-3710.

[11] M. Yuan, Y.G. Li, E.B Wang, C.G. Tian, L. Wang, C.W. Hu, N.H. Hu, H.Q. Jia. Modified polyoxometalates: hydrothermal syntheses and crystal structures of three novel reduced and capped Keggin derivatives decorated by transition metal complexes, Inorg. Chem. 42 (2003) 3670-3676.

[12] J. Liu, J.N. Xu, Y.B. Liu, Y.K. Lu, J.F. Song, X. Zhang, X.B. Cui, J.Q. Xu, T.G. Wang. Hydrothermal synthesis and characterization of the tri-capped and mono-supported pseudo-Keggin-type tungstovanadophosphate: $\left\{\mathrm{PW}_{4}{ }^{\mathrm{VI}} \mathrm{W}_{5}{ }^{\mathrm{V}} \mathrm{V}^{\mathrm{IV}}\right.$ $\left.\mathrm{O}_{40}\left(\mathrm{~V}^{\mathrm{IV}} \mathrm{O}\right)_{3}\left[\mathrm{Cu}(\mathrm{en})_{2}\right]\right\}_{6}$, J. Solid. State. Chem. 180 (2007) 3456-3462.

[13] J.Q. Sha, J. Peng, H.S. Liu, J. Chen, A.X. Tian, P.P. Zhang. Asymmetrical polar modification of a bivanadium-capped Keggin POM by multiple $\mathrm{Cu}-\mathrm{N}$ coordination polymeric chains, Inorg. Chem. 46 (2007) 11183-11189.

[14] X. López, C. d. Graaf, J.M. Maestre, Marc Bénard, M.M. Rohmer, C. Bo, J. M. Poblet. Highly reduced polyoxometalates: $a b$ initio and DFT study of $\left[\mathrm{PMo}_{8} \mathrm{~V}_{4} \mathrm{O}_{40}(\mathrm{VO})_{4}\right]^{5-}$ J. Chem. Theory. Comput. 1 (2005) 856-861.

[15] Y. Yu, H.Y. Ma, H.J. Pang, S.B. Li, T.T. Yu, H. Liu, C.Y. Zhao, Z.F. Zhang, Two novel zipper-like compounds of the usual and bivanadyl capped Keggin clusters connected by propeller-shaped complexes. New J. Chem. 38 (2014) 1271-1276. 
[16] Y. Zhang, J.Q. Shen, L.H. Zheng, Z.M. Zhang, Y.X. Li, E.B. Wang. Four polyoxonibate-based inorganic-organic hybrids assembly from bicapped heteropolyoxonibate with effective antitumor activity, Cryst. Growth. Des. 14 (2014) 110-116.

[17] P. Huang, E.L. Zhou, X.L. Wang, C.Y. Sun, H.N. Wang, Y. Xing, K.Z. Shao, Z.M. $\mathrm{Su}$, New heteropolyniobates based on a bicapped Keggin-type $\left\{\mathrm{VNb}_{14}\right\}$ cluster with selective adsorption and photocatalytic properties, CrystEngComm, 16 (2014) 9582-9585.

[18] S.Y. Shi, H.H. Teng, L.M. Chang, Y.Wang, L.N. Xiao, X.B. Cui, J.Q. Xu. New compounds constructed from bi-antimony capped Keggin polyoxoanions and different coordination fragments, Inorg. Chim. Acta. 399 (2013) 172-176.

[19] Z.X. Zhang, Masahiro Sadakane, Toru Murayama, Norihito Sakaguchi, Wataru Ueda. Preparation, structural characterization, and ion-exchange properties of two new zeolite-like 3D frameworks constructed by $\varepsilon$-Keggin-Type polyoxometalates with binding metaions, $\mathrm{H}_{11.4}\left[\mathrm{ZnMo}_{12} \mathrm{O}_{40} \mathrm{Zn}_{2}\right]^{1.5-}$ and $\mathrm{H}_{7.5}\left[\mathrm{Mn}_{0.2} \mathrm{Mo}_{12} \mathrm{O}_{40} \mathrm{Mn}_{2}\right]^{2.1-}$, Inorg. Chem. 53 (2014) 7309-7318.

[20] J.Y. Niu, X. Fu, J.W. Zhao, S.Z Li, P.T. Ma, J.P. Wang. Two-dimensional polyoxoniobates constructed from Lindqvist-Type hexaniobates functionalized by mixed ligands, Cryst. Growth. Des. 10 (2010) 3110-3119.

[21] Z.X. Zhang, M. Sadakane, T. Murayama, W. Ueda. Investigation of the formation process of zeolite-like 3D frameworks constructed with $\varepsilon$-Keggin-type polyoxovanadomolybdates with binding bismuth ions and preparation of a nano-crystal. Dalton Trans. 43 (2014) 13584-13590.

[22] W.B. Yang, C.Z. Lu, X.P. Zhan, H.H. Zhuang. Hydrothermal synthesis of the first vanadomolybdenum polyoxocation with a "Metal-Bonded" spherical Framework. Inorg. Chem. 41 (2002) 4621-4623.

[23] L.J Dong, R.D. Huang, Y.G. Wei, W. Chu. A remarkable member of the polyoxometalates: the Eight-Nickel-Capped $\alpha$-Keggin polyoxoazonickelate Inorg. Chem. 48 (2009) 7528-7530.

[24] C. Lei, J.G. Mao, Y. Q. Sun and J. L. Song. A novel organic-inorganic hybrid based on an 8-electron-reduced Keggin polymolybdate capped by tetrahedral, trigonal bipyramidal, and octahedral zinc: synthesis and crystal structure of $\left(\mathrm{CH}_{3} \mathrm{NH}_{3}\right)\left(\mathrm{H}_{2}\right.$ bipy $)\left[\mathrm{Zn}_{4}(\text { bipy })_{3}\left(\mathrm{H}_{2} \mathrm{O}\right)_{2} \mathrm{Mo}_{8}{ }_{8} \mathrm{Mo}^{\mathrm{VI}}{ }_{4} \mathrm{O}_{36}\left(\mathrm{PO}_{4}\right)\right] \cdot 4 \mathrm{H}_{2} \mathrm{O}$, Inorg. Chem. 43 (2004) 1964-1968. 
[25] H. Zhang, K. Yu, C.M. Wang, Z.H. Su, C.X. Wang, D. Sun, H.H. Cai, Z.Y. Chen, B.B. Zhou. $\mathrm{pH}$ and ligand dependent assembly of Well-Dawson arsenomolybdate capped architectures. Inorg. Chem. 53 (2014) 12337-12347.

[26] H. Miao, G.H. Hu, J.Y. Guo, H.X. Wan, H. Mei, Y. Zhang, Y. Xu. Syntheses, structures and properties of two new organic-inorganic hybrid materials based on $\varepsilon$-Zn Keggin units $\left\{\varepsilon-\mathrm{PMo}_{8}{ }_{8} \mathrm{Mo}^{\mathrm{VI}}{ }_{4} \mathrm{O}_{40-\mathrm{x}}(\mathrm{OH})_{\mathrm{x}} \mathrm{Zn}_{4}\right\}$. Dalton Trans. 44 (2015) 694-700.

[27] Q. Lan, Z.M. Zhang, Y.G. Li, Y. Lu, En-Bo Wang. Synthesis of a poly-pendant 1-D chain based on 'trans-vanadium' bicapped Keggin-type vanadtungstate and its photocatalytic properties. Dalton Trans. 43 (2014) 16265-16269.

[28] A. Taleb, C. Petit, M. P. Pileni. Optical properties of self-assembled 2D and 3D superlattices of silver nanoparticles. J. Phys. Chem. B. 102 (1998) 2214-2220.

[29] P.P Zhang, J. Peng, H.J. Pang, J.Q Sha, M. Zhu, D.D. Wang, M.G Liu. The factors affecting on the assembly of $\mathrm{Ag}-\mathrm{H}_{2}$ biim system: size, charge or shape of polyanions. CrystEngComm. 13 (2011) 3832-3841.

[30] J. Lü, F. X. Xiao, L. X. Shi, R. Cao. Synthesis, structure and luminescent property of a new hybrid solid based on Keggin anions and silver-organonitrogen fragments. J. Solid. State. Chem. 181 (2008) 313-318.

[31] L.S. Felices, P. Vitoria, J.M. Gutiérrez-Zorrilla, L.Lezama, S. Reinoso, Hybrid inorganic-metalorganic compounds containing copper(II)-monosubstituted Keggin polyanions and polymeric copper(I) complexes, Inorg. Chem. 45 (2006) 7748-7757. 


\section{Figure captions}

Fig. 1. View of the basic structural unit and the coordination environments for the $\mathrm{SiW}_{12}$ cluster and $\mathrm{Ag}^{+}$ions in $\mathbf{1}$ (symmetry codes: \#1: 1-x, 2-y, -z;). All the hydrogen atoms attached to phen molecules are omitted for clarity.

Fig. 2. Combined ball/stick/polyhedral representation of bi-silver-capped silicotungstate polyanion [(Agphen $\left.)_{2} \mathrm{SiW}_{12} \mathrm{O}_{40}\right]^{2-}$ in $\mathbf{1}$.

Fig. 3. View of the $1 \mathrm{D}$ supramolecular chain in $\mathbf{1}$, showing the $\pi \cdots \pi$ interactions between two neighboring $[\mathrm{Ag}(1) \text { phen }]^{+}$coordination fragments.

Fig. 4. (Left) Absorption spectra of the $M B$ aqueous solution during the photodegradation under $250 \mathrm{~W}$ Hg-lamp irradiation; (Right) Conversion rate of MB (K) vs the irradiation time (t). 


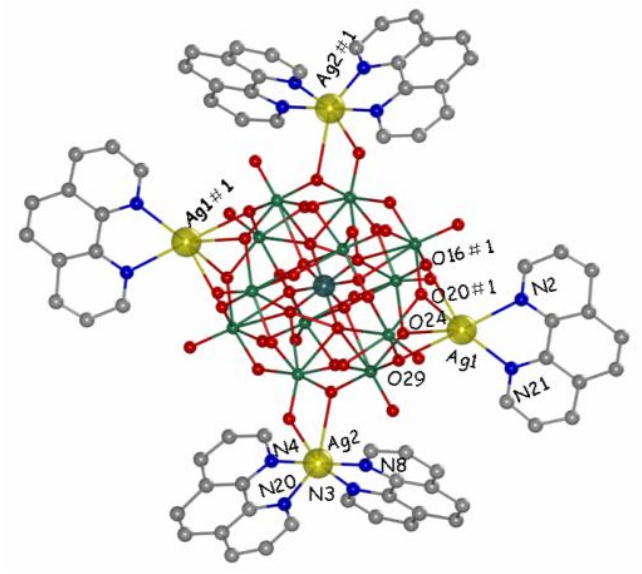

Fig. 1. View of the basic structural unit and the coordination environments for the $\mathrm{SiW}_{12}$ cluster and $\mathrm{Ag}^{+}$ions in $\mathbf{1}$ (symmetry codes: \#1: 1-x, 2-y, -z;). All the hydrogen atoms attached to phen molecules are omitted for clarity. 

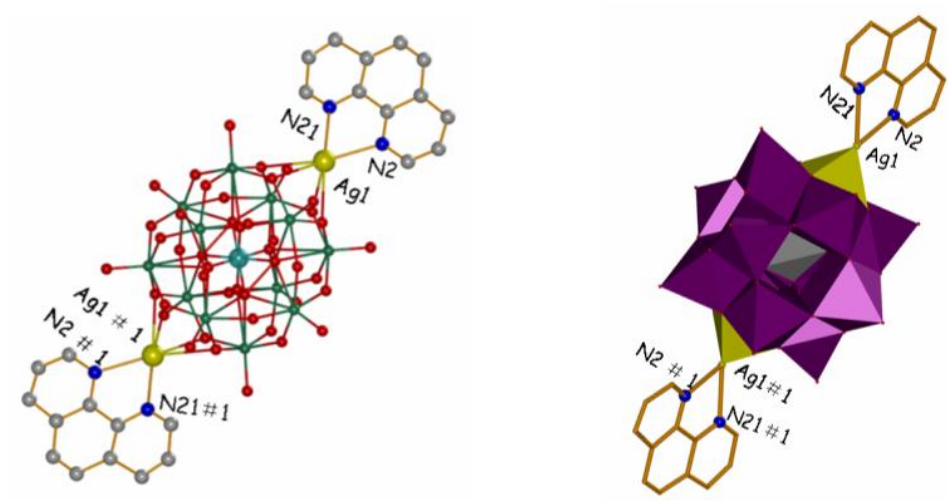

Fig. 2. Combined ball/stick/polyhedral representation of bi-silver-capped silicotungstate polyanion [(Agphen $\left.{ }_{2} \mathrm{SiW}_{12} \mathrm{O}_{40}\right]^{2-}$ in $\mathbf{1}$ 


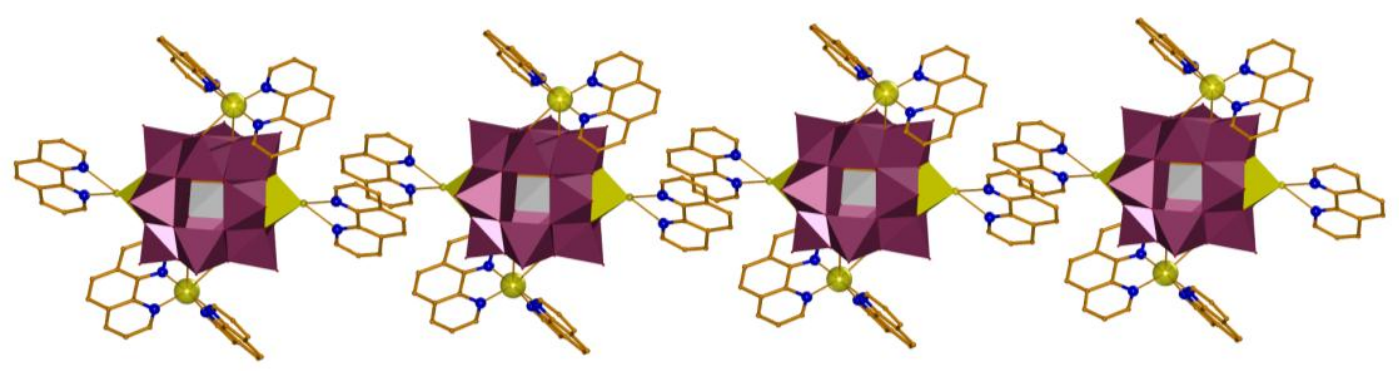

Fig. 3. View of the 1D supramolecular chain in 1, showing the $\pi \cdots \pi$ interactions between two neighboring $[\operatorname{Ag}(1) \text { phen }]^{+}$coordination fragments. 

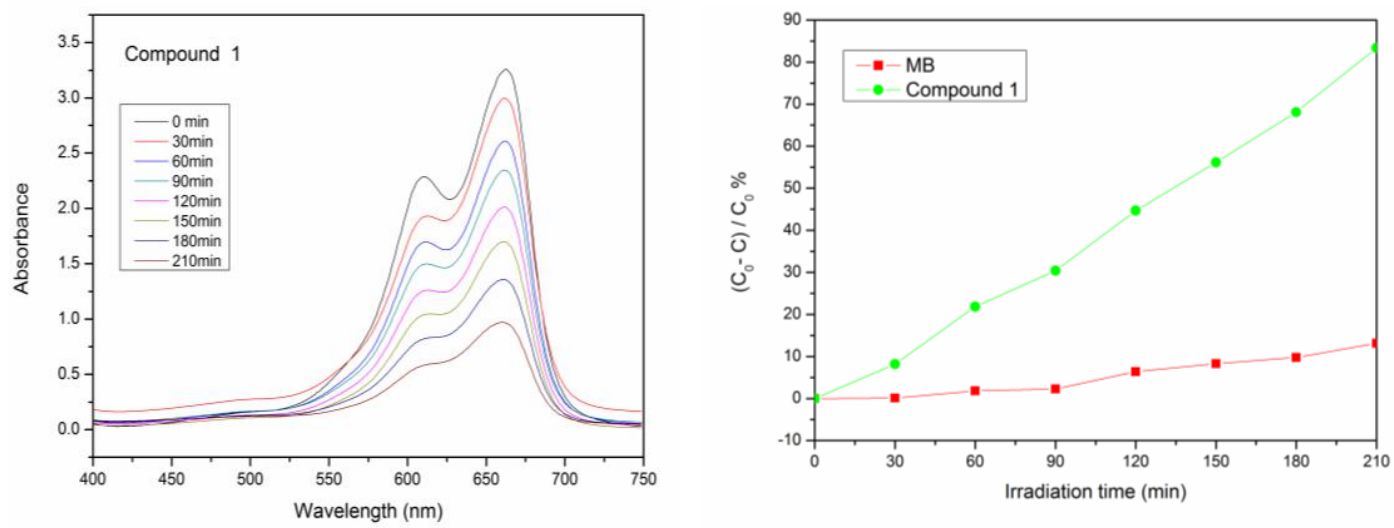

Fig. 4. (Left) Absorption spectra of the MB aqueous solution during the photodegradation under $250 \mathrm{~W}$ Hg-lamp irradiation; (Right) Conversion rate of MB (K) $v s$ the irradiation time (t). 
Synthesis, Structure and Photocatalytic Property of a New Hybrid Compound Based on Unusual Bi-Silver-Capped

\section{Polyoxometalates}

Haijun Pang ${ }^{a}$, Ying $\mathrm{Niu}^{a}, \mathrm{JiaYu}^{b *}$, Huiyuan $\mathrm{Ma}^{a}{ }^{a * *}$, Qingfei Song ${ }^{b}$, Shaobin $\mathrm{Li}^{a}$
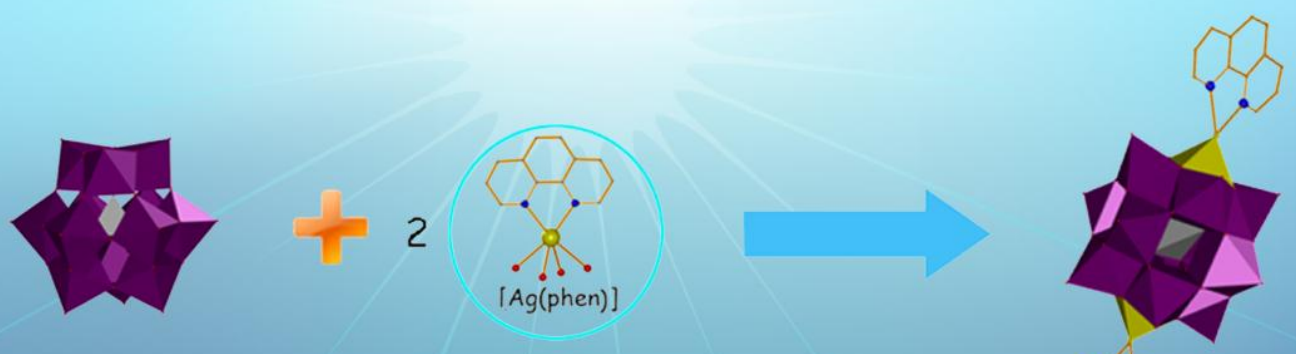

$\operatorname{SiW}_{12}$

Graphical abstract 
Synthesis, Structure and Photocatalytic Property of a New Hybrid Compound Based on Unusual Bi-Silver-Capped

\section{Polyoxometalates}

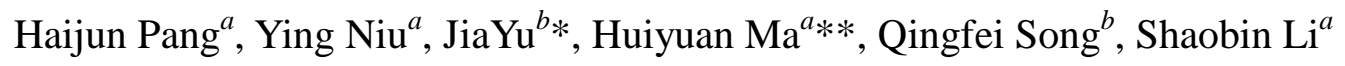

8 pages

A hybrid compound consisting of an unprecedented bi-silver-capped polyoxometalates has been hydrothermally synthesized, and its photodecomposition behavior towards Methylene Blue has been investigated. 